Maria Altberg*

Pontifícia Universidade Católica do Rio de Janeiro / CAPES

\title{
"Pensar com as mãos": o radical processo de intertextualidade godardiana em Imagem e
} Palavra

Resumo: O ponto de partida deste artigo é o longa-metragem Imagem e Palavra (2018), de Jean-Luc Godard, ancorado na ideia do "pensar com as mãos". A manipulação de sons e imagens, prática característica da obra do cineasta, é radicaliza e levada ao extremo neste seu filme-livro. As opções estéticas e os procedimentos de montagem apresentados proporcionam uma experiência de suspensão dos sentidos. Entramos em contato com uma linguagem que, livre de um télos, funde-se com a própria experiência de vida. A partir da tapeçaria artística e política tecida por Godard, o artigo convocará outros teóricos e artistas que, ao eleger o desvio da normalidade como virtude, realizaram o desafiador percurso de pensar histórias que resistem ao(s) tempo(s).

Palavras-chave: Jean-Luc Godard, pensar com as mãos, linguagem, suspensão, montagem

Abstract: The starting point of this article is the feature film The Image Book (2018), by Jean-Luc Godard, anchored in the idea of "thinking with your hands". A conspicuous characteristic of the filmmaker's work, the manipulation of sounds and images, is taken to the limit in this film-book. The aesthetic options and editing procedures presented provide an extreme sensorial experience. This thought-provoking language, free of a télos, merges with life itself. Based on the artistic and political tapestry woven by Godard, the article invites theorists and artists who, escaping from normality, made the challenging journey of thinking stories that can resist time(s).

Keywords: Jean-Luc Godard, thinking with your hands, language, sensorial experience, editing

[...] o crítico se instala naquele terreno intermediário entre o estado ético, de um lado, e o estado estético-criativo, de outro; não pertence a nenhum dos dois, seu lugar é essa zona intermediária, o que, de um ponto de vista sociológico, significa que ele se situa entre as classes e entre as épocas, que ele encontra seus confrades ali onde se preparam as revoluções (explícitas ou silenciosas), as resistências, as subversões.

Max Bense 
[...] toda imagem é antes de tudo um enigma armado, um bloco de sentido que escorregou para fora da linguagem e que interrompe em nós o fluxo do pensamento.

Jean-Christophe Bailly

É possível pensar que a ideia da mão que escreve sempre esteve presente no cinema de Jean-Luc Godard. $O$ início de sua carreira foi influenciado pelo ensaio-manifesto de Alexandre Astruc, "Nascimento de uma nova vanguarda: a câmera-caneta", ${ }^{2}$ publicado na revista L'Écran Français em 1948. ${ }^{3}$ O conceito de câmera-caneta sugeria que o ato de filmar deveria adquirir a mesma fluidez da escrita manual. No primeiro plano de Imagem e Palavra ${ }^{4}$ (2018), o filme mais recente de Godard, há um recorte da tela São João Batista de Leonardo da Vinci, de uma mão com o dedo indicador apontado para cima. A imagem é apresentada em preto e branco, sem as cores da pintura original. Logo adiante, há um plano de um par de mãos manipulando rolos de película em uma moviola enquanto ouve-se a narração do diretor em voice over a respeito dos cinco sentidos, as cinco partes do mundo, os cinco dedos da fada que juntos formam a mão. 0 plano seguinte mostra outro par de mãos escrevendo a lápis em um papel e, no final da sequência, a narração segue com a citação do escritor suíço Denis de Rougemont: "A verdadeira condição do homem: pensar com as mãos". ${ }^{5} \mathrm{Em}$ seguida vem um trecho que mostra a escultura $A$ Mão, de Giacometti, em composição com um letreiro onde se lê: "L'Image". É possível identificar este último fragmento como pertencente a Histórias(s) do Cinema (1988-1998), série antológica de Godard.

Logo na introdução de Imagem e Palavra, o já quase nonagenário cineasta deixa clara a radicalização da ideia de experimentação e manipulação das imagens e sons no cinema, desde sempre presente em sua profícua obra, e que se apresentará elevada a uma alta potência ao longo dos oitenta e quatro minutos de filme. A relação de Godard com o cinema sempre foi de pensamento atravessado pela inventividade. Iniciou como crítico da revista Cahiers du Cinéma na década de cinquenta e é um dos principais expoentes da celebrada Nouvelle Vague. Passando pelo coletivo documentarista Dziga Vertov, de viés maoísta, no fim da década de sessenta, retoma o experimentalismo da forma nos anos oitenta e noventa. História(s) do Cinema permanece como seu mais ambicioso projeto, um ensaio épico e pessoal sobre a arte cinematográfica. No século XXI, segue experimentando as possibilidades da linguagem em títulos como Elogio ao Amor (2001), Nossa Música (2004), Filme Socialismo (2010) e Adeus à Linguagem (2014). Palavra e Imagem retoma o formato de citação em fragmentos de História(s) do Cinema, atualizando o trabalho de colagem de materiais e os temas. 0 título original em francês é Le Livre d'Image. Ao ser questionado em entrevista por que optou por "image" no singular, alterando a expressão do que em português traduz-se por "livro ilustrado" (livre d'images), Godard responde: "É a imagem que faz o livro. A potência do texto é domi- 
nada pela imagem. É matéria de imagem, como na pintura" (Godard 2018: s.p.). ${ }^{6}$ Neste seu álbum de imagens dividido em cinco capítulos (acrescidos de um segmento final), ${ }^{7}$ o cineasta constrói uma miscelânea audiovisual a partir de pedaços de filmes diversos da história do cinema (alguns de sua autoria), imagens amadoras de câmeras de segurança e de telefones celulares, e ainda fotografias, pinturas e textos, percorrendo um labirinto vertiginoso de temas. Cinema, política, guerras e religiões aparecem em forma de sequências disruptivas, com saturações e contrastes na imagem, superposições e supressões de elementos em operações de montagem que lançam o espectador em uma experiência nada alentadora.
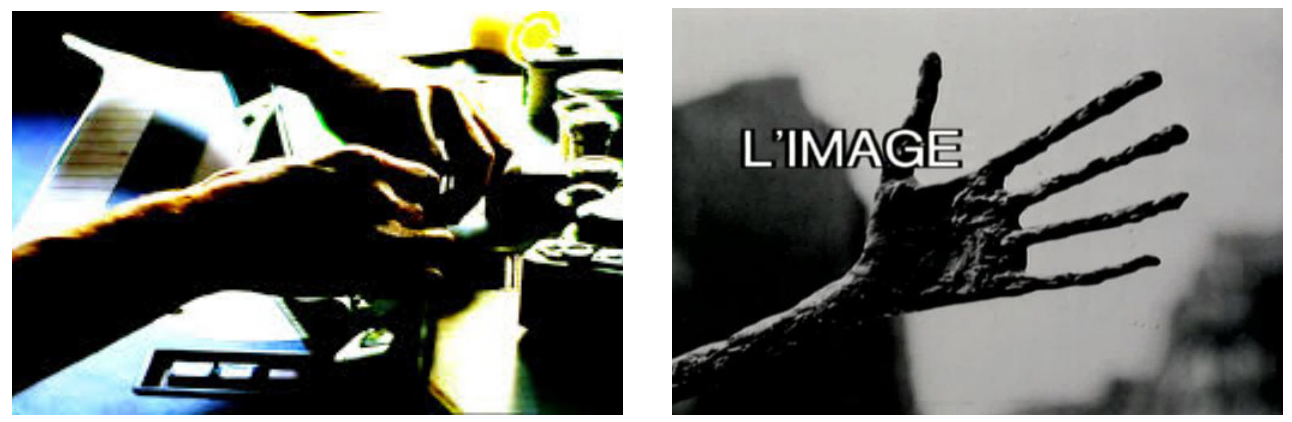

Figs. 1 e 2: o trabalho manual da moviola / a escrita de Godard sobre A Mão de Giacometti (frames de Imagem e Palavra)

As sensações de confusão e arrebatamento que o filme causa remetem à descoberta das inscrições rupestres pré-históricas nas cavernas francesas de Lascaux (em 1940) e Chauvet (em 1994, consideradas mais antigas em quinze mil anos que as primeiras). Tal revelação fez emergir no século XX discursos fortes acerca de um marco inicial do que conhecemos como arte. $O$ desvelamento das pinturas de figuras do cotidiano de nossos ancestrais, em sua maioria de grandes animais de caça, segue a instigar teóricos e artistas. George Bataille escreveu, sob o impacto da visita que fez à gruta de Lascaux em 1955:

O que sabemos dos homens que de si deixaram apenas estas sombras inapreensíveis, isoladas de qualquer pano de fundo? Quase nada. Apenas que estas sombras são belas, tão belas aos olhos como as mais belas pinturas dos nossos museus. Mas das pinturas dos nossos museus sabemos a data, o nome do autor, o tema, o destino. [...] As pinturas que temos à nossa frente são miraculosas, transmitem-nos uma forte e íntima emoção. Mas são por isto tanto mais ininteligíveis. [...] E esta beleza incomparável e a simpatia que ela desperta deixam-nos, por causa disto, penosamente em suspenso. (Bataille 2015: 18-19)

Na construção cacofônica de Imagem e Palavra, ao não informar as fontes de suas citações audiovisuais no momento em que as mesmas surgem na tela (apenas em rápida 
listagem nos créditos finais), Godard parece nos deixar em um estado de suspensão e alerta semelhante ao provocado pelas pinturas dos homens de Lascaux e Chauvet. Se "o que parece digno de ser amado é sempre o que nos transtorna, o inesperado, o inesperável" (idem: 21), a ausência de dados informativos sobre aquilo que nos é apresentado aos olhos e ouvidos, da mesma maneira que nos desorienta, nos lança na experiência libertadora da surpresa pelo que é da ordem do indizível (para além do dito) ou insonhável (para além do sonhado).

Outro jogo de que Godard lança mão em Imagem e Palavra é a escolha por inserir legendas do que é dito somente em alguns pontos do filme. Mesmo para o espectador fluente na língua francesa, em muitos momentos a voz de Godard, que já carrega um intrínseco tom grave, é alterada por distorções. Também acontece de essa voz e de outros elementos sonoros do filme serem abruptamente suprimidos enquanto se tenta assimilar determinadas passagens, o que contribui para uma sensação de confusão dos sentidos. Tomemos uma dessas passagens: na primeira parte do filme, o capítulo intitulado "Remakes", há uma cena de Johnny Guitar (1954), western dirigido por Nicholas Ray. A imagem, carregada de saturação e contraste em relação ao filme original, realça o azul dos olhos de Joan Crawford. A cena mostra um diálogo entre Crawford e Sterling Hayden, em que o personagem masculino pede juras de amor, ainda que mentirosas, à mulher. A imagem é subitamente cortada, enquanto o som continua com algumas falas. A imagem retorna, o diálogo segue por alguns segundos e a cena toda é interrompida drasticamente enquanto a atriz está pronunciando uma das mentiras. A tela preta que segue é acompanhada do som de um filme do próprio Godard, O Pequeno Soldado (1963), em que o personagem de Michel Subor também demanda, a alguém que ainda não vemos, falsas palavras de amor. A imagem que surge em seguida revela Anna Karina em cena com Subor no filme, mas o som não está em sincronia com a imagem.

Já que é tarefa frustrante tentar traduzir a experiência que o filme proporciona numa habitual descrição de cenas, a tentativa aqui será, pois, buscar apontar alguns procedimentos que o filme realiza e associar alguns pensamentos e manifestações artísticas a sensações que o filme gera. De volta à caverna de Chauvet: "Não temos palavras para essa escuridão", afirma John Berger em ensaio poético. "Não é noite nem é ignorância. De tempos em tempos todos nós cruzamos essa treva, vendo tudo: tanta coisa que não conseguimos distinguir nenhuma" (Berger 2004: 36). Imagem e Palavra promove um encontro de imagens e sons de fontes e tempos distintos para uma dança de embates, porém na tela não há hierarquia entre as partes. Um cinéfilo aplicado seria capaz de reconhecer muitos dos títulos que aparecem embaralhados, como A General (1926), de Buster Keaton, Alemanha Ano Zero (1948), de Roberto Rosselini, ou Elefante (2003), de Gus Van Sant, para citar uma ínfima porção do repertório apresentado. Porém as aparições são como rastros, já que praticamente nenhuma imagem é apresentada em seu estado original, mas intensamente alterada em sua forma. Ressignificadas em conjunto, as imagens parecem emergir através da tela, assim como Berger enxergou os traços nos calcários de Chauvet: 
A "perspectiva" nômade é sobre coexistência, não distância. [...] No fundo da caverna, o que significava no fundo da terra, havia de tudo: vento, água, fogo, lugares distantes, os mortos, trovão, dor, trilhas, animais, luz, o não nascido... Estava tudo ali na rocha para ser convocado. As famosas impressões de mãos em tamanho natural (se as olhamos dizemos que são nossas) - essas mãos estão lá, impressas em ocre, para tocar e marcar o estar-presente de todas as coisas e a fronteira última do espaço que essa presença habita. [...] Todo o drama, que na arte mais recente se torna uma cena pintada sobre uma superfície com beiradas, está compactado ali na aparição que veio através da rocha a fim de ser contemplada. (Berger 2004: 39)

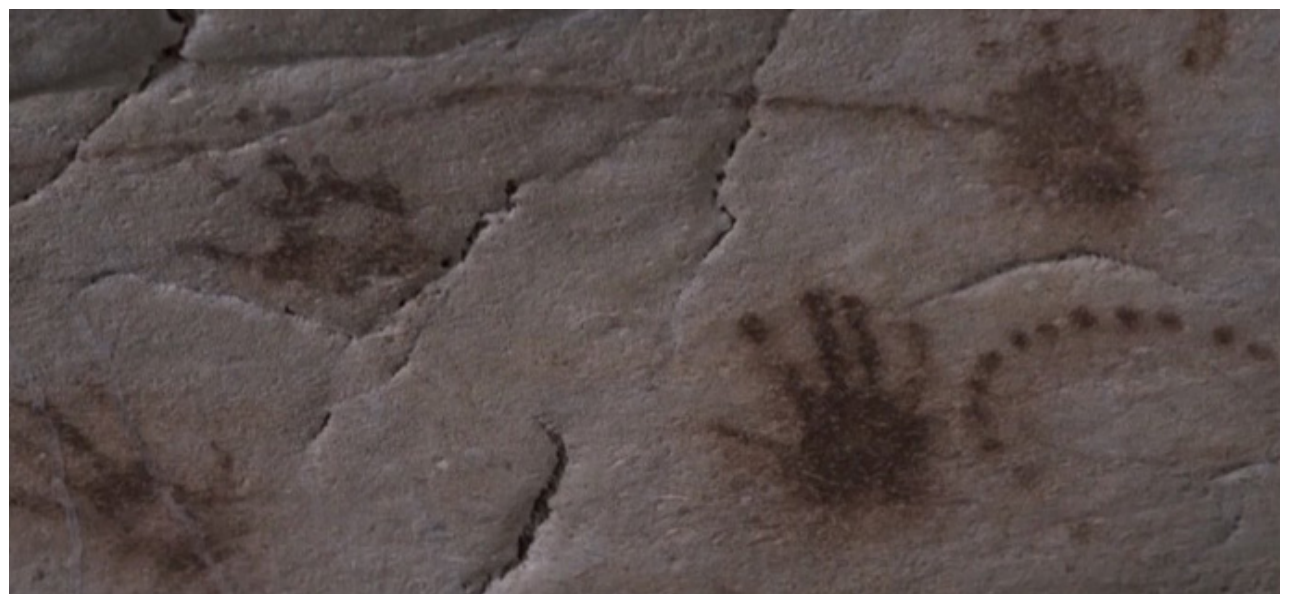

Fig. 3: "assinatura do artista" na caverna de Chauvet $^{8}$

O resultado da manipulação dos arquivos em Imagem e Palavra evidencia o caráter difuso que Georges Didi-Huberman atribui a certas imagens, entendidas "ao mesmo tempo como documento e como objeto de sonho, como obra e objeto de passagem, como monumento e objeto de montagem" (Didi-Huberman 2012: 215). O processo de montagem desenvolve uma reescritura da memória intrínseca aos arquivos, adicionando múltiplas camadas ao mero índice de real das imagens. É na montagem que Godard desenvolve plenamente o exercício de liberdade criativa, ao apostar na potência do fragmento e na força poética do trabalho com arquivos. Em sua artesania empregada na ilha de edição, opera a máxima da dialética eisensteiniana, que define os planos como células em constante colisão entre si: "montagem é conflito. [...] Conflito dentro do plano é montagem potencial, que, no desenvolvimento de sua intensidade, esfacela a prisão quadrilátera da tomada e explode o seu conflito em impulsos de montagem entre as peças da montagem" (Eisenstein apud Campos 1977: 158). O livro de imagens de Godard é todo construído a partir de choques entre os elementos visuais e sonoros, que esgarçam o limiar entre os planos. O filme ainda exerce colisões dentro de uma mesma tomada, 
operando decomposições e destruições da imagem (em procedimentos estéticos como o glitch ${ }^{9}$ e demais efeitos).

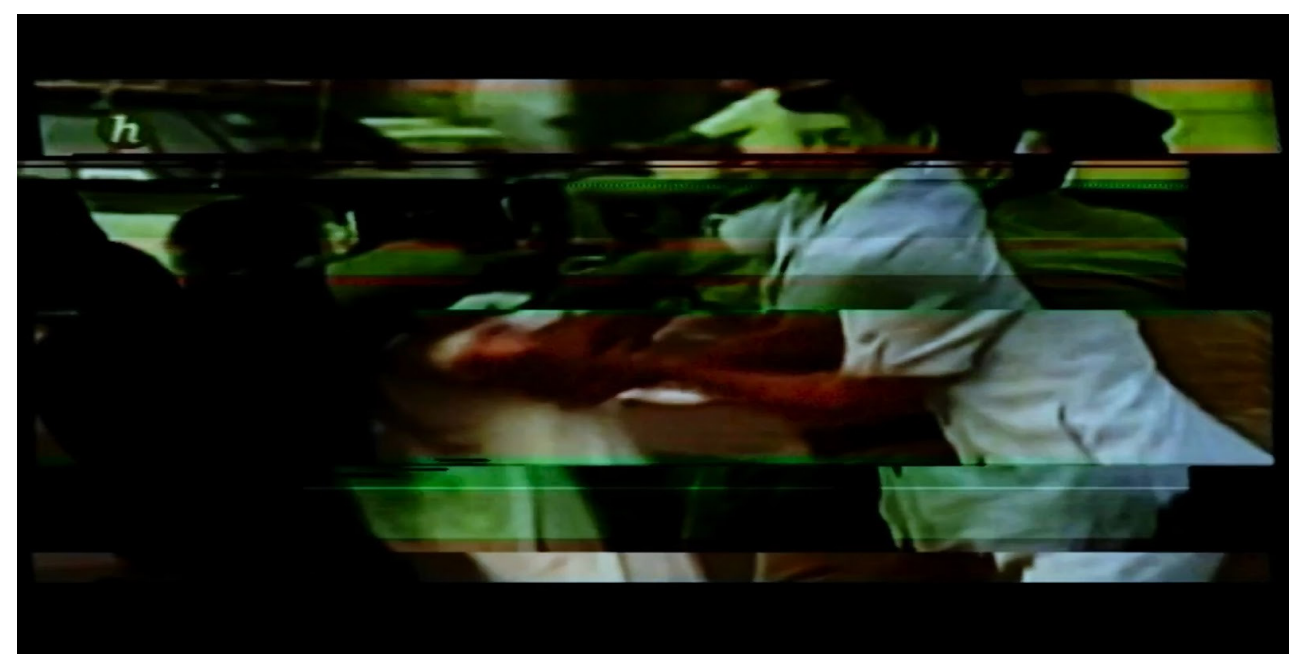

Fig. 4: imagem retorcida pela mão de Godard (frame de Imagem e Palavra)

Eisenstein defendia que a base do ideograma japonês marcava uma forma de vida cinematográfica. A reunião de símbolos na formação dessa escrita assemelhava-se, segundo o cineasta russo, ao processo de montagem, com suas faíscas e disputas internas. Quem também se interessou com entusiamo pela escrita ideogramática foi Ernest Fenollosa, que enxergava um aspecto extremamente poético e metafórico na composição dos caracteres da China:

Quanto mais concreta e vividamente expressamos as interações das coisas, melhor é a poesia. [...] Não podemos exibir a opulência da Natureza por simples adição, amontoando sentenças. O pensamento poético trabalha por sugestão, acumulando o máximo de significado numa única frase replena, carregada, luminosa de brilho interior. (Fenollosa 1977: 132)

Fenollosa via, na relação entre os elementos da escrita poética chinesa, a sugestão de um movimento constante. Essa escrita estaria mais próxima da ideia de linguagem como forma de vida sugerida por Wittgenstein, uma língua constituída da experiência do viver e não apenas um sistema de representação. A linguagem deve ser aquela que está em toda parte e em lugar nenhum. Declaradamente influenciado pelo filósofo austríaco, Godard também desvia do caráter limitador da linguagem em Imagem e Palavra: "as palavras nunca serão a linguagem", frase que, expressa já nos créditos finais do filme, designa o seu pensar com as mãos, um ato fora da intelecção e do conheci- 
mento, a junção entre o corpo e a alma, o dentro e o fora. O processo artístico exposto no filme de Godard bagunça os sentidos, "faz gaguejar a língua corrente" (Deleuze/Guattari 1991: 228), produz vibrações no contato com um universo em que dúvida e saber têm pesos equivalentes, em uma construção diegética que parece negar a própria ideia de narrativa. Deleuze, em seus Diálogos com a jornalista Claire Parnet, demonstra admiração por processos criativos que envolvem as metáforas de captura e roubo, segundo ele, característicos de artistas como Bob Dylan e o próprio Godard:

Quando Godard diz: gostaria de ser um escritório de produção, é claro que não quer dizer: quero produzir meus próprios filmes, ou quero editar meus próprios livros. Ele quer dizer apenas idéias, pois, quando se chega a esse ponto, se está sozinho, mas se é também como uma associação de malfeitores. Não se é mais um autor, é-se um escritório de produção, nunca se esteve mais povoado. Ser um "bando": os bandos vivem os piores perigos, reformar os juízes, tribunais, escolas, famílias e conjugalidades, mas o que há de bom em um bando, em princípio, é que cada um cuida de seu próprio negócio encontrando ao mesmo tempo os outros; cada um tira seu proveito, e que um devir se delineia, um bloco, que já não é de ninguém, mas está "entre" todo mundo, se põe em movimento como um barquinho que crianças largam e perdem e que outros roubam. (Deleuze/ Parnet 1998: 17)

Godard conta com seu bando de malfeitoras ideias em Imagem e Palavra, realizando uma pilhagem audiovisual, uma torrente de associações própria das formas ensaísticas em toda sua potência de experimentação. Seu exercício intertextual prescinde da revelação das fontes das citações, já que o filme se faz no próprio ato de manejar o que é aludido. A escrita fílmica do cineasta dá a ver, mais que uma apropriação que simplifica obras alheias, uma prática transformadora de si e do mundo - o que para Foucault (1998: 12), na forma de ensaios, estaria mais próximo do corpo vivo do pensamento filosófico. Já na parte final do filme, uma voz feminina entoa, sobre a tela preta sem imagens: "Quando falo comigo mesmo, falo palavras de outros como se eu falasse demais de mim".

Em Imagem e Palavra, é possível reconhecer dimensões políticas constantes na filmografia de Godard, como a crítica às religiões dogmáticas ou às reincidentes guerras no mundo árabe geradas pela cobiça por petróleo - o segmento final, intitulado "Feliz Arábia”, faz referência a um fictício reino do Golfo, o único onde não haveria o ouro negro e, portanto a paz reinaria. Contudo, compreendemos tais posturas não porque expressas em um tratado linear e objetivo (por mais que o filme se estruture em capítulos), mas porque diluídas pelo domínio de uma linguagem capaz de concatenar elementos em fluxo vibrante, mesmo que numa tapeçaria aparentemente irregular e caótica, criando esboços de pensamentos que logo se esvaem para dar lugar a outros, como constelações. Como a ideia de pensamento tátil de de Jean-Christophe Bailly sobre a escrita ensaística: 
não aquilo que acontece quando duas peças de um quebra-cabeça se unem, mas o que ocorre se saltamos de um ponto a outro, como quando seguimos o que é chamado de passo japonês, que se diz em inglês, acredito, stepping stone. Um percurso que não seria, por consequência, nem uma pura consecução lógica, nem um movimento errático, e muito menos um tipo de via média com propriedades de ambos, mas sim um livre desdobramento e uma travessia atenta movida por uma espécie de avidez. (Bailly 2017:14)

Como Wittgenstein, Godard recusa o limite dito instransponível entre o verbal e o não verbal, elegendo a incompreensão como virtude. O caminho que rejeita uma linguagem presa a definições objetivas também é o norte da vida/obra/dança do mestre do butô Kazuo Ohno. Em Treino e $(m)$ Poema, uma tentativa de tradução poética de seus treinamentos em forma de livro, Ohno afirma: "Se não nos arriscamos a desviar do percurso estabelecido, se não saímos do que é chamado normalidade, não se torna dança" (Ohno 2016: 52). A linguagem inusitada (porque inesperável) de seus "ideo-corpo-gramas" (Verdi apud Ohno 2016: 17) se faz na permanente mudança de curso que nos transporta à escuridão vertiginosa do abismo, penetrando em nosso inconsciente. "Conversar com um louco é um privilégio inestimável”, diz Godard em Imagem e Palavra.

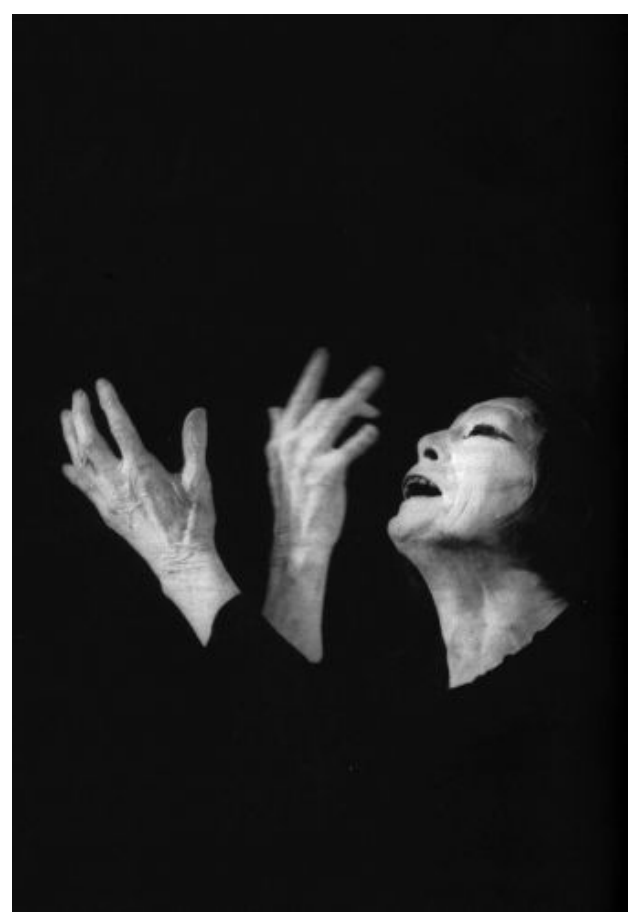

Fig. 5: gestual de Kazuo Ohno 
Na década posterior à criação do butô, o cineasta e poeta Pier Paolo Pasolini escreveu, numa espécie de argumento-manifesto do filme A Raiva (1963):

O que aconteceu no mundo depois da guerra e do pós-guerra?

A normalidade.

Já, a normalidade.

No estado de normalidade não se olha ao redor, tudo ao redor se apresenta como "normal", sem a excitação e emoção dos anos de emergência. O homem tende a se adormecer na própria normalidade, se esquece de refletir, perde o hábito de se julgar, não sabe mais se perguntar quem é.

É então que se cria artificialmente o estado de emergência. E quem o faz são os poetas. Os poetas, estes eternos indignados, estes modelos da raiva intelectual e da fúria filosófica. (Pasolini 1962: s.p.)

Pasolini é um dos signos da constelação de Imagem e Palavra em trecho de Salò (1975). Não fosse seu bárbaro assassinato ao cinquenta e três anos, teria seguido escrevendo e filmando, movido por essa indignação criadora. Kazuo Ohno faleceu três anos após ultrapassar um século de vida (tendo dançado até os noventa e um) e Jean-Luc Godard, aos oitenta e nove, segue investindo sua "fúria contra o clichê" (Carson 2008: s.p.) em cada novo filme. ${ }^{10} \mathrm{Em}$ Imagem e Palavra, sua ira é também contra a língua como um crivo provisório na desordem do mundo, no desejo de uma outra escrita que se imiscua na própria vida. O movimento é o de criar mundos dentro deste mundo saturado de tantas imagens e palavras - como ele vocifera no filme: "a terra abandonada, sobrecarregada de letras do alfabeto e sufocada sob o peso do conhecimento", ou em passagem anterior: "O ato da representação quase sempre envolve violência junto ao sujeito da representação".

A permanência na catástrofe vai ao encontro da ideia de Chthuluceno trazida por Donna Haraway. Em contraponto a conceitos que seriam simples diagnósticos históricos, como o Antropoceno e o Capitaloceno, a teórica estadunidense defende outras formas de enxergar o contexto, considerando um tempo que, mais que um ponto exato na evolução, atravessa passado, presente e porvir em um movimento serpenteante:

Chthuluceno como uma necessária terceira história, um terceiro saco de redes [netbag] para a coleta do que é crucial para o processo, para permanecer no problema. Os chthônicos não estão confinados num passado apagado. Eles estão zumbindo, ferroando, sugando enxames e os seres humanos não estão numa pilha composta separada. Somos humus, não Homo, nem Antropos; somos adubo, não pós-humanos. Como sufixo, a palavra kainos, '-ceno', sinaliza novo, recentemente feito, nova época desse presente espesso. Para renovar o poder biodiverso da terra, há o trabalho simpoiético e o jogo do Chthuluceno. Especificamente, ao contrário do Antropoceno e do Capitaloceno, o Chthuluceno é feito de processos narrativos 
de multiespécies e de práticas de se-tornar-com que permanecem em jogo, em tempos precários, onde o mundo não tenha terminado e o céu não tenha caído - ainda. (Haraway 2016: s.p.)

Na temporalidade contínua e tentacular do Chthuluceno, segundo Haraway, viveriam seres humanos e não humanos que cultivam a capacidade de permanecer no problema, condição para a resistência em um mundo de permanentes autodestruições e refazimentos. Estaríamos em uma zona de contínua tensão, relegados sempre ao lado dos derrotados. Esse estado de angústia seria inerente ao existir, na visão Clarice Lispector: "o que é vivo, por ser vivo, se contrai" (Lispector apud Antelo 2011: 32).

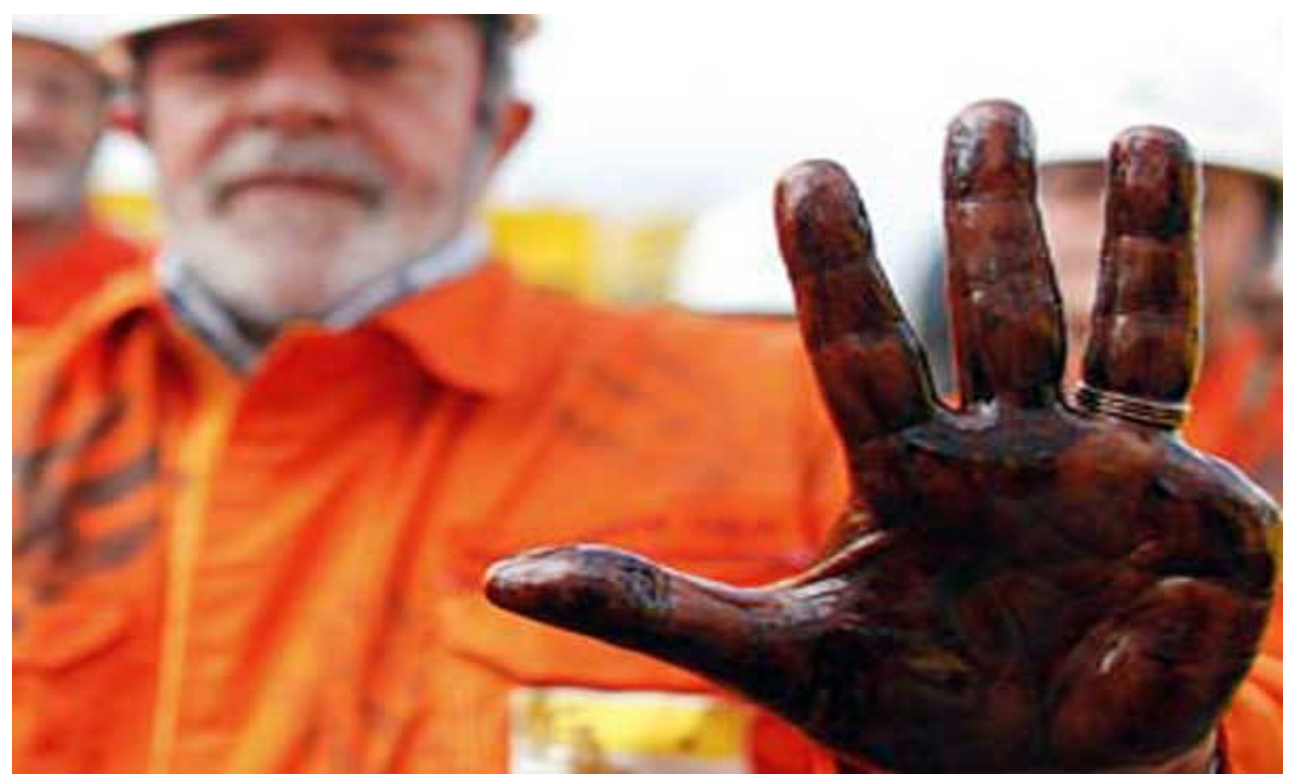

Fig. 6: a mão operária que teve o dedo ceifado na linha de produção / mão humanitária que livra um povo da fome / mão soberana que descobre em águas profundas o óleo que atiça a cobiça imperialista

“O que podemos fazer com este mundo em mutação?”, indaga Godard em seu livro de imagens. Sua resposta está no próprio processo de tessitura (e concomitante destruição dos elementos) do filme, colocando em disputa uma quantidade enorme de temporalidades e espacialidades. No universo estético e político godardiano, conhecimento e ação se igualam, "porque as histórias já foram contadas e são mais lentas que as ações”, ele diz. Ao desnaturalizar a linha evolutiva da humanidade como única forma de organização possível e ao se desontologizar a linguagem, poderemos sempre voltar à escuridão indivisível da caverna, "descobrir nosso caminho para dentro do espaço daquelas primeiras pinturas” (Berger 2004: 38). Uma das última falas de Godard, em tom ofegante, 
nos diz: "E ainda que nada aconteça como esperávamos, isso não muda em nada a nossa esperança. Eles permanecem desejando esta necessária utopia”.

Imagem e Palavra reúne diversos planos de mãos que reforçam o conceito de pensar com as mãos. Podemos imaginar mãos que anacronicamente convergem temporalidades: a mão com o mindinho torto do primeiro artista gravada no calcário; a mão precisa do calígrafo chinês; a mão contorcida do butô; a mão esquálida esculpida por Giacometti; a que corta e cola os fotogramas na moviola; a mão que aciona a bomba atômica; a que escreve poesia: todas elas a serpentear, no desafio de contar histórias que resistam ao(s) tempo(s).

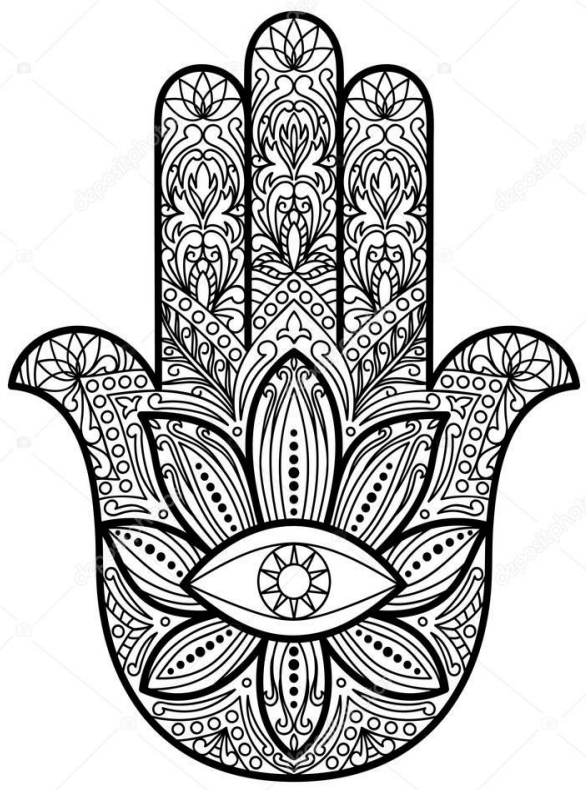

Fig. 7: hamsá, a mão que olha ${ }^{11}$ 


\section{NOTAS}

* Maria Altberg é doutoranda do Programa de Literatura, Cultura e Contemporaneidade da Pontifícia Universidade Católica do Rio de Janeiro e bolsista CAPES. Sua pesquisa aborda arquivos sonoros da palavra falada como elemento de intertextualidade na montagem criativa de ensaios audiovisuais. Atua profissionalmente como montadora de cinema e televisão, tendo colaborado em diversas obras documentais e de ficção.

${ }^{1}$ O presente trabalho foi realizado com apoio da Coordenação de Aperfeiçoamento de Pessoal de Nível Superior - Brasil (CAPES) - Código de Financiamento 001.

2 "Naissance d'une Nouvelle Avant-Garde: la Caméra-stylo". Tradução nossa.

${ }^{3}$ Astruc (apud Oricchio 2010: s.p.) escreve: “Depois de ter sido sucessivamente uma atração de feira, um divertimento análogo ao teatro de boulevard, ou meio de preservar as imagens da época, ele (o cinema) se torna pouco a pouco uma linguagem. Uma linguagem, quer dizer, uma forma na qual e pela qual um artista pode exprimir seu pensamento, por mais abstrato que ele seja, ou traduzir suas obsessões exatamente como acontece hoje no ensaio e no romance. É por isso que chamo essa nova época do cinema a era da câmera-caneta."

${ }^{4}$ Adotarei sempre no artigo o título traduzido no Brasil. Em Portugal, o filme foi lançado como O Livro de Imagem. ${ }^{5} \mathrm{~A}$ fonte da citação é informada somente nos créditos finais do filme. Jean Starobinski associa essa ideia de Rougemont aos escritos de Michel de Montaigne, autor que inaugurou a prática da escrita de ensaio, em que se descobria a subjetividade do autor: “'Pensar com as mãos', nisto se aplicava Montaigne, ele cujas mãos estavam sempre em movimento, mesmo que tenha se declarado inapto para qualquer trabalho manual; é preciso saber ao mesmo tempo meditar e manejar a vida." (Starobinski 2011: 17).

6 "C'est l'image qui fait le livre. La puissance du texte est dominée par l'image. C'est de l'image-matière, comme dans la peinture." Tradução nossa.

${ }^{7}$ Os títulos dos capítulos são: "Remakes”, "As noites de São Petersburgo", "Estas flores perdidas entre os trilhos, no vento confuso da viagem", "O espírito das leis", "A região central” e "Feliz Arábia".

${ }^{8}$ Logo após sua descoberta em 1994, a caverna de Chauvet foi fechada ao público para que se preservassem suas pinturas. O cineasta Werner Herzog obteve permissão para entrar com uma equipe mínima e realizar o filme A Caverna dos Sonhos Esquecidos (2010). A partir de registros das inscrições e poucas entrevistas com cientistas, Herzog chama a atenção para um traço comum nas repetidas mãos gravadas nas paredes de pedra: uma imperfeição no dedo mindinho. A assinatura recorrente indicaria que um mesmo artista de dedo torto teria se ocupado dos desenhos entre os homens da comunidade.

${ }^{9}$ Glitch é uma palavra em iídiche - do alemão glitschen, "deslizar", "escorregar" - e foi introduzida na linguagem da informática para designar um mau funcionamento. A Glitch Art é um movimento artístico que manipula erros eletrônicos em busca de determinados resultados estéticos em imagens, numa linguagem que procura se aproximar do mundo digital.

${ }^{10}$ Ainda nos primeiros meses da pandemia mundial causada pelo novo coronavírus, Godard participou, de sua casa em Rolle, na Suíça, de uma live de quase duas horas, em que conversou com Lionel Baier, diretor da ECAL (Escola de Arte de Lausanne).

${ }^{11}$ De origem árabe, a palavra hamsá traduz-se por "cinco", em referência aos cinco dedos da mão. É tida como um amuleto contra o mau olhado em doutrinas não ocidentais, como o judaísmo, o islamismo e o budismo. 


\section{BIBLIOGRAFIA}

Antelo, Raul (2011), "A pesquisa como desejo de vazio”, Anais do I Seminário dos alunos de pós-graduação em literatura da Universidade Federal de Santa Catarina, Conferência de abertura, Florianópolis: 08-39.

Astruc, Alexandre (1948), "Naissance d'une Nouvelle Avant-Garde: la Caméra-stylo", L'Écran Français, $\mathrm{n}^{\circ} 144$.

Bailly, Jean-Christophe (2017), "O ensaio, uma escrita extensível”, in O ensaio e a anedota, tradução de Leda Cartum e Laura Erber, Rio de Janeiro, Zazie: 5-23.

Bataille, George (2015), o Nascimento da arte, tradução de Aníbal Fernandes, Lisboa, Sistema Solar.

Berger, John (2004), “A caverna de Chauvet”, in Bolsões de resistência, tradução de Lya Luft, Barcelona, Gustavo Gili: 33-40.

Carson, Anne (2008), "Variações sobre o direito de se manter em silêncio", tradução de Caetano W. Galindo, originalmente in A Public Space, $\mathrm{n}^{\circ} 7$.

Deleuze, Gilles / Guattari, Félix (1992), O que é a filosofia?, Rio de Janeiro, Ed. 34.

-- / Parnet, Claire (1998), “Uma conversa: o que é, para que serve?”, in Diálogos, São Paulo, Escuta: 7-45.

Didi-Huberman, Georges (2012), "Quando as imagens tocam o real”, in Pós: Revista do Programa de Pós-graduação em Artes da EBA/UFMG. Belo Horizonte, v.2, n 4, 204219.

Eisenstein, Sergei (1977), "O princípio cinematográfico e o ideograma”, in Campos, Haroldo (org.), Ideograma: lógica, poesia, linguagem, São Paulo, Cultrix: 149-166.

Fenollosa, Ernest (1977), "Os caracteres da escrita chinesa como instrumento para a poesia, in Campos, Haroldo (org.), Ideograma: lógica, poesia, linguagem, São Paulo, Cultrix: 109-148.

Foucault, Michel (1998), "Introdução", in História da sexualidade 2: O uso dos prazeres, Rio de Janeiro, Graal: 7-26.

Godard, Jean-Luc (2019), "Entretien exclusive à propôs du "Livre d’image”, <https:// www.lesinrocks.com/2019/04/16/cinemas/cinemas/entretien-exclusif-avec-godard-a-propos-du-livre-dimage/> (último acesso em 04/03/20).

Haraway, Donna (2016), "Pensamento tentacular: Antropoceno, Capitaloceno, Chtuluceno", tradução de Filipe Barros, originalmente in e-flux, $\mathrm{n}^{\circ} 75$.

Ohno, Kazuo (2016), Treino e (m) Poema, São Paulo, n-1 edições.

Oricchio, Luiz Zanin (2010), "Godard: escrever com a camera”, < https://cultura.estadao.com.br/blogs/luiz-zanin/godard-escrever-com-a-camera/ > (ultimo acesso em 25/06/2019).

Pasolini, Pier Paolo (1962), "A Raiva”, in Vie Nuove, n 38.

Starobinski, Jean (2011), "É possível definir o ensaio?, tradução de Bruna Torlay, in Remate de Males, Campinas: 13-24. 
REDE INTERNACIONAL LYRACOMPOETICS

Maria Altberg

Wittgenstein, Ludwig (1999), Investigações filosóficas, tradução de José Carlos Bruni, São Paulo, Nova Cultural.

\section{Filmes citados:}

Bruckman, Clyde / Keaton, Buster, A General, Estados Unidos, 1926.

Godard, Jean-Luc, Adeus à Linguagem, França/Suíça, 2014.

--, Elogio ao Amor, França/Suíça, 2001.

--, Filme Socialismo, França/Suíça, 2010.

--, História(s) do Cinema, França, 1988-1998.

--, Nossa Música, França/Suíça, 2004.

--, Palavra e Imagem, França/Suíça, 2018.

Herzog, Werner, A Caverna dos Sonhos Esquecidos, França/EUA/Reino Unido/Canadá/Alemanha, 2010.

Pasolini, Pier Paolo, Salò, Itália/França, 1975.

Ray, Nicholas, Johnny Guitar, Estados Unidos, 1954. 